\title{
Dental erosion in a group of British 14- year-old, school children. Part I: Prevalence and influence of differing socioeconomic backgrounds.
}

\author{
Y. H. Al-Dlaigan, ' L. Shaw, ${ }^{2}$ and A. Smith, ${ }^{3}$
}

\begin{abstract}
Objectives To establish the prevalence of erosion in a cluster random sample of 14- year-olds in Birmingham UK. To determine whether socioeconomic group influences the prevalence of erosion.
\end{abstract}

Methods The study group consisted of a cluster random sample of 14-year-old school children in Birmingham UK: 418 children were examined from 12 different schools; 209 were male and 209 female. The level of tooth wear was recorded using a modification of the (TWI) index of Smith and Knight (1984). The ACORN classification was used to assess the socioeconomic status of all children.

Results Results showed that $48 \%$ of the children had low erosion, $51 \%$ had moderate erosion and only $1 \%$ had severe erosion. There were statistically significant differences between males and females; more males had buccal/ labial and lingual / palatal tooth surface erosion than females (Chi-square analysis $\mathrm{P}$ $<0.001)$. There was also significantly more erosion observed in teenagers in the lowest socioeconomic categories.

Conclusion It was concluded that moderate levels of dental erosion are common in 14-year-old school children and this may lead to increasing clinical problems. There was significantly more erosion in children from low socioeconomic groups. Possible aetiological factors need to be investigated further.

\footnotetext{
There has been considerable attention in recent times focused on 1 the problems of tooth surface loss in both adults and children. An extensive series of articles on this topic in recent British Dental Journals has considered the problems and some of the practicalities of their solution. ${ }^{1-11}$ There has been a distinct clinical impression among dental practitioners, particularly those who see a large number of children and young people, that this is an increasing problem. Although tooth wear is undoubtedly due to a combination of erosion, abrasion and attrition, in the younger population it is the contribution from erosion that appears to be increasing disproportionately. However, reliable prevalence data are difficult to find and at present it is still impossible to prove and quantify any possible increase. The surveys often suffer from deficiencies of sample selection as well as poor reproducibility of the diversity of the diagnostic indices used. The most reliable data have come from UK based investigations; the largest study undertaken was that of

$1^{*}$ Research Fellow, ${ }^{2}$ Senior Lecturer in Paediatric Dentistry, ${ }^{3}$ Professor of Oral Biology, The University of Birmingham, School of Dentistry, St Chads, Queensway, Birmingham, B4 6NN

${ }^{\star}$ Correspondence to: $Y$. H. Al-Dlaigan

REFEREED PAPER

Received 14.01.00; Accepted 13.07.00

(c) British Dental Journal 2001; 190: 145-149
}

the UK Child Dental Health Survey of $1993^{12}$ which showed that $52 \%$ of 5 year olds, and $25 \%$ of 11 year olds had significant erosion. Two other studies have been published in 14 year olds showing 30\% affected in Liverpool ${ }^{13}$ and $57 \%$ in the South East of England. ${ }^{14}$

Although the true prevalence of dental erosion amongst the general population requires further investigation, there is now increasing evidence available on the aetiology. It is known to be multifactorial with individual susceptibility factors related to anatomy, salivary flow rates and composition as well as to intrinsic sources of acid from gastro-oesophageal reflux and extrinsic dietary acid.

Some of this evidence is contradictory and the proportional contribution of these factors to the overall development of erosion is uncertain. ${ }^{15,16}$ The extrinsic sources of acid that are available are many and varied but there has been considerable media publicity as well as scientific research, on the enormous increase in soft drink consumption that has taken place in the last 25 years. ${ }^{17,18}$ Much of the published research has involved very selected samples or case control studies and there is very little available information from the general population.

There is also little information about more general influences on the prevalence of erosion. It has been noted by Millward et al. ${ }^{19}$ that socioeconomic group had a significant effect on the prevalence of erosion in 4-year-old children. Children from higher socioeconomic groups had more severe erosion, but they also had better oral hygiene. It is possible that these young children were showing the effects of increased abrasion during toothbrushing following acid challenges to the teeth. Davis and Winter ${ }^{20}$ and Jaeggi and Lussi ${ }^{21}$ reported significant acceleration of toothbrush abrasion following demineralization caused by exposure to dietary acids. In those children with poor oral hygiene, plaque deposits may actually provide a protective effect against erosion.

Further information is therefore needed not only to establish the extent of the problem in the general population, but also to try to quantify possible related and causative factors so that a preventive regimen can be targeted at susceptible groups. Consideration of socioeconomic background will be a critical feature of such studies.

The aims of this study were, first to establish the prevalence of erosion in a cluster random sample of 14-year-olds in Birmingham UK. Secondly, to determine whether socioeconomic group influences the prevalence of erosion in this age group.

\section{Methods}

A cluster random sample of 14-year-olds was drawn from South Birmingham UK; this was as part of the 14-year-old BASCD survey (British Association for the Study of Community Dentistiry). In total there were 1,988 14-year-old children attending 35 different schools in South Birmingham; 12 of these schools were selected as 
Table I The proportion and numbers of children examined in different schools.

\begin{tabular}{llccl}
\hline Type of School & Gender & $\begin{array}{c}\text { Number of } \\
\text { children examined }\end{array}$ & $\begin{array}{c}\text { Number of children on } \\
\text { Nominal Roll (\%) }\end{array}$ \\
\hline A Comprehensive & Mixed & 54 & 78 & $(69)$ \\
B Comprehensive & Girls & 49 & 117 & $(42)$ \\
C Comprehensive & Mixed & 47 & 62 & $(75)$ \\
D Comprehensive & Mixed & 45 & 76 & $(59)$ \\
E Comprehensive & Boys & 41 & 52 & $(78)$ \\
F Comprehensive & Mixed & 30 & 47 & $(63)$ \\
G Comprehensive & Girls & 28 & 50 & $(56)$ \\
H Comprehensive & Mixed & 28 & 50 & $(56)$ \\
I Comprehensive & Boys & 24 & 47 & $(51)$ \\
J Grammar & Mixed & 24 & 46 & $(52)$ \\
K Grammar & Boys & 24 & 34 & $(70)$ \\
L Grammar & Girls & 24 & 43 & $(56)$ \\
\hline
\end{tabular}

representative of the social and ethnic mix. There were 3 girl's schools, 3 boy's schools and 6 mixed schools. Three of them were grammar schools and nine were comprehensives. Table 1 shows the numbers and proportions of children examined in the different schools. Not all of the children were available on the days of the examination; some were not present in school and some children had to leave for specific classes. In one large girls' comprehensive school only approximately half of the pupils were examined so that the male/female proportions remained representative. A total of 418 children were sampled; 209 were males and 209 were females. They, and their parents/ carers gave informed consent to participate in this study and ethical approval was given by the Birmingham Research Ethics Committee.

All the children were examined clinically within their schools under standard illumination from a Daray light using number 6 plane mouth mirrors. The surfaces of all teeth present in the mouth were scored for dental erosion according to the criteria shown in Table 2. This is based on the Tooth Wear Index of Smith and Knight, ${ }^{22}$ with minor modifications. It has been used previously in several epidemiological investigations. All the children were examined by the same person (Y.H.A) who had previously undergone extensive training and calibration exercises in the use of this index.

Table 2 TWI criteria Smith and Knight ${ }^{22}$ modified by Millward et al. ${ }^{19}$

\begin{tabular}{|c|c|c|}
\hline $\begin{array}{l}\text { Code: } \\
\text { Scores }\end{array}$ & Surfaces & Criteria \\
\hline 0 & $\mathrm{~B} / \mathrm{L} / \mathrm{I}$ & No loss of enamel surface characteristics. \\
\hline I & $\mathrm{B} / \mathrm{L} / \mathrm{O} / \mathrm{I}$ & Loss of enamel surface characteristics. \\
\hline 2 & $\mathrm{~B} / \mathrm{L} / \mathrm{O}$ & $\begin{array}{l}\text { Loss of enamel, visible dentine for less than } \mathrm{I} / 3 \text { of the surface. } \\
\text { Loss of enamel just exposing dentine. }\end{array}$ \\
\hline 3 & $\begin{array}{l}\mathrm{B} / \mathrm{L} / \mathrm{O} \\
\mathrm{I}\end{array}$ & $\begin{array}{l}\text { Loss of enamel, visible dentine for }>1 / 3 \text { of the surface. } \\
\text { Loss of enamel and substantial loss of dentine but not } \\
\text { exposure of pulp or secondary dentine. }\end{array}$ \\
\hline 4 & $\mathrm{~B} / \mathrm{L} / \mathrm{O}$ & $\begin{array}{l}\text { Complete loss of enamel, or pulp exposure, or secondary } \\
\text { dentine. }\end{array}$ \\
\hline 9 & $\mathrm{I} / \mathrm{L} / \mathrm{O} / \mathrm{I}$ & $\begin{array}{l}\text { Pulp exposure or exposure of secondary dentine. } \\
\text { Excluded from analysis (missing tooth, partially erupted, } \\
\text { orthodontic band, composite restoration, any crowns, tooth } \\
\text { fracture, and fissure sealant). }\end{array}$ \\
\hline
\end{tabular}

B,Buccal or Labial; L, Lingual or Palatal; O, Occlusal; I,Incisal.

Two calibration studies to assess intra and inter-examiner reproducibility were organised. The intra-examiner reproducibility was assessed on a group of 20 children aged between 12 to 15 years and gave a rate of $97 \%$ agreement and 0.91 weighted Kappa statistic value. The inter-examiner reproducibility study involved a different group of 20 children of a similar age; this showed a $95 \%$ percentage reproducibility between the two examiners and 0.80 weighted Kappa statistic value, thus indicating a very high level of agreement in scoring the index.

The data were recorded by a trained assistant. In cases of doubt the lower score was assigned. All the children were classified into one of the following groups based on their individual tooth surface scores. (The incisal edges of maxillary and mandibular anterior teeth were excluded before categorisation due to the potentially high levels of attrition which would have invalidated measurement of tooth surface loss due predominantly to erosion):

- Any child with scores of 0 and 1 was placed in the Low erosion group.

- Any child with scores of 2 was placed in the Moderate erosion group.

- Any child with scores of 3 and/ or 4 was placed in the Severe erosion group.

In order to determine the socio-economic background of each child, the ACORN Category (A Classification of Residential Neighbourhoods in UK $)^{23}$ was used based on the postcode for each child, which reflected the area in which the child lived rather than their individual characteristics. This system was originally developed for marketing purposes and has subsequently been used in epidemiological surveys. ${ }^{24}$ Fifty-four different types of housing areas are defined which are merged into 17 social groups. There are six ACORN categories covering those 17 groups and these are defined in Table $3 .{ }^{24}$

All data were analysed using SPSS and Survey Plus. The Chisquare test for non-parametric data was used for the ACORN classification for socio-economic background. Significance was accepted at the $\mathrm{p}<0.05$ level.

Table 3 ACORN Categories Classification. ${ }^{24}$

\begin{tabular}{|c|c|c|}
\hline \multicolumn{2}{|c|}{ Acorn categories } & \multirow{2}{*}{$\begin{array}{l}\text { Acorn groups } \\
\text { Wealthy achievers in suburban areas. Affluent greys in } \\
\text { rural communities. Prosperous pensioners in retirement } \\
\text { areas. }\end{array}$} \\
\hline A & Thriving & \\
\hline B & Expanding & $\begin{array}{l}\text { Affluent executives in family areas. Well-off workers in } \\
\text { family areas. }\end{array}$ \\
\hline C & Rising & $\begin{array}{l}\text { Affluent urbanities in town and city areas. Prosperous } \\
\text { professionals in metropolitan areas. Better-off } \\
\text { executives in inner city areas. }\end{array}$ \\
\hline D & Settling & $\begin{array}{l}\text { Comfortable middle agers and mature home owning } \\
\text { areas. Skilled workers and home owning areas. }\end{array}$ \\
\hline$E$ & Aspiring & $\begin{array}{l}\text { New home owners in mature communities. White collar } \\
\text { workers and better off multi-ethnic areas. }\end{array}$ \\
\hline$F$ & Striving & $\begin{array}{l}\text { Older people in less prosperous areas. Council estate } \\
\text { residents. People in multi-ethnic areas and low-income } \\
\text { areas. }\end{array}$ \\
\hline
\end{tabular}

\section{Results}

After classifying the total 418 children (209 males and 209 females) into groups based on their tooth surface scores, excluding incisal and occlusal surfaces, it was found that the prevalence of dental erosion was $48 \%$ with low erosion, $51 \%$ had moderate erosion and only $1 \%$ had severe erosion. There were statistically significant differences between males and females; more males had buccal/ labial and lingual / palatal tooth surface erosion than females (Chi-square test $\mathrm{P}<0.001)$. The percentage of males and females placed in each of the categories is given in Table 4 .

The majority of tooth surfaces showed loss of enamel surface characteristics (score 1) in both upper and lower teeth and buccal and lingual surfaces. The incisal edges of most anterior teeth (central incisors, lateral incisors and canine teeth) had more tooth tissue loss with visible dentine (score 2). Erosion into dentine was most common on the upper and lower buccal surfaces of anterior teeth compared with posterior teeth. Very little tooth wear was seen on premolars and molars. 
Table 4 Prevalence and severity of erosion in 418, 14-year-olds, Birmingham, U.K school children, males and females.

\begin{tabular}{|c|c|c|c|c|c|c|}
\hline \multirow[t]{2}{*}{$\begin{array}{l}\text { Level of } \\
\text { erosion }\end{array}$} & \multicolumn{2}{|c|}{$\begin{array}{l}\text { Male } \\
(209)\end{array}$} & \multicolumn{2}{|c|}{$\begin{array}{c}\text { Female } \\
(209)\end{array}$} & \multicolumn{2}{|c|}{$\begin{array}{l}\text { Total } \\
(4 \mid 8)\end{array}$} \\
\hline & Number & $\begin{array}{l}\text { (\%) of total } \\
\text { Males }\end{array}$ & Number & $\begin{array}{l}\text { (\% ) of total } \\
\text { Females }\end{array}$ & Number & (\%) \\
\hline $\begin{array}{l}\text { Low } \\
\text { erosion }\end{array}$ & 96 & (46) & 106 & (5I) & 202 & (48) \\
\hline $\begin{array}{l}\text { Moderate } \\
\text { erosion }\end{array}$ & 109 & (52) & 103 & (49) & 212 & $(5 \mathrm{I})$ \\
\hline $\begin{array}{l}\text { Severe } \\
\text { erosion }\end{array}$ & 4 & (2) & 0 & (0) & 4 & (I) \\
\hline
\end{tabular}

Figure 1 shows the percentage of each type of tooth surfaces ascribed to the different erosion scores: $79.7 \%$ of all buccal and labial surfaces had scores of 0 to 1 indicating low levels of erosion and $9.1 \%$ of these surfaces were given a score of 2 indicating visible dentine for less than one third of the surfaces. Very few surfaces, only $0.1 \%$, had scores of $3 / 4$, and $12.1 \%$ were excluded. A common reason for exclusion was the presence of fixed orthodontic appliances. Of lingual or palatal surfaces, $92.4 \%$ had scores of $0-1,0.6 \%$ had scores of 2 and $7 \%$ were excluded. Figures 2 and 3 show the percentage distribution of erosion scores for all surfaces and for all upper and lower teeth.

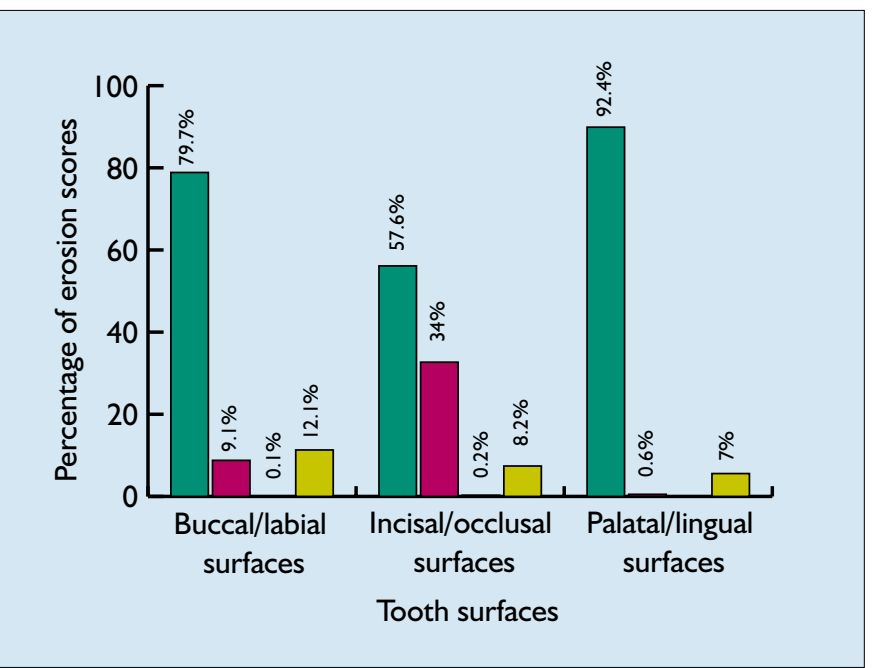

Fig. I Erosion in 418, I4-year-old Birmingham school children.

Percentage of different types of tooth surfaces affected. Green, scores $0-1$; red, score 2; purple, score 3-4; yellow, score 9 excluded.

The percentage of children with different levels of erosion according to the ACORN categories is given in Table 5. Severe erosion was only found in the Aspiring and Striving categories. Significantly more erosion was found in the 'Striving' group with 39\% showing low erosion, $60 \%$ moderate and $1 \%$ severe erosion. This contrasts with children in the 'Thriving' group, 69\% having low erosion and only $31 \%$ with moderate erosion and no severe erosion detected. These differences were statically significant (Chi-square $\mathrm{P}<0.001$ ). This 'Striving' category includes the low-income and less prosperous areas.

\section{Discussion}

Investigation of erosion taking a random sample of 14-year-olds was undertaken for several reasons. First, this is an age when most of the permanent teeth have erupted and certainly the incisors and first molars will have been present in the mouth for a number of years. They will therefore have been exposed to the possible intrinsic

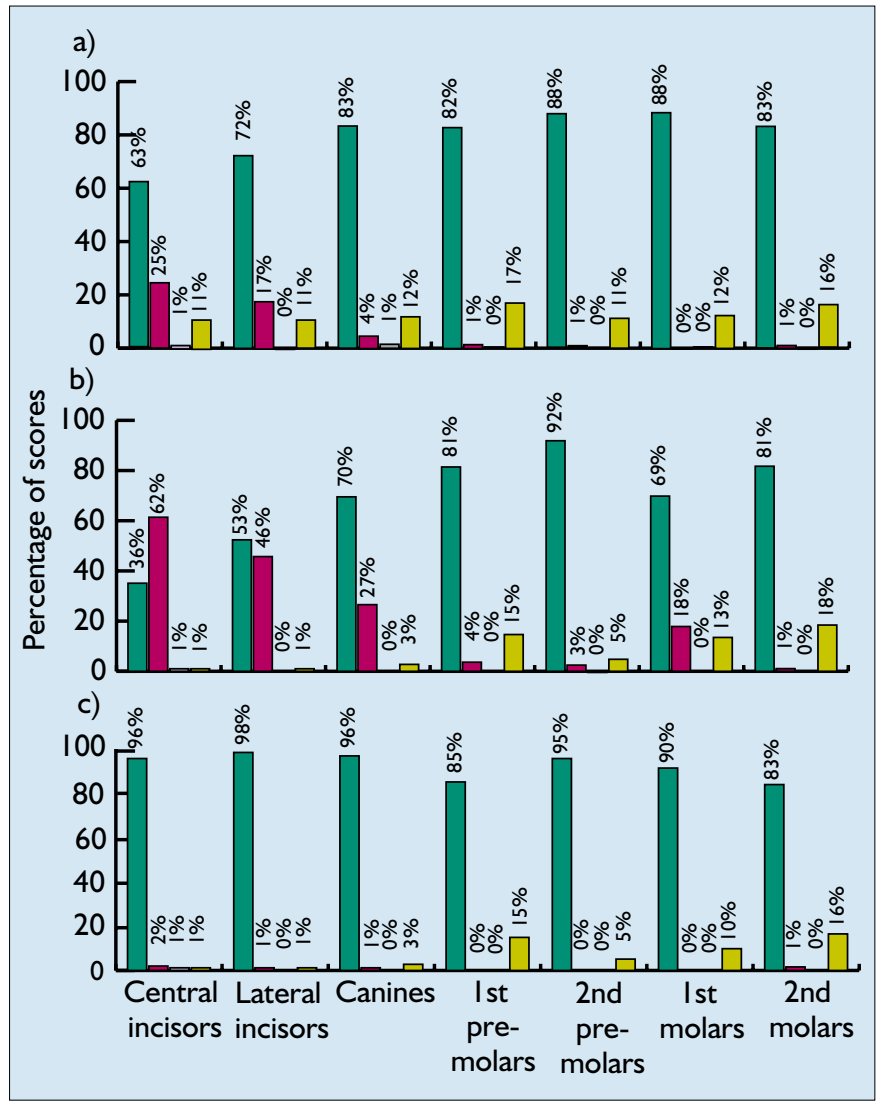

Fig. 2 Erosion in 418, 14-year-old Birmingham school children. a, Percentage of erosion scores for buccal/labial surfaces of upper teeth. $b$, Percentage of erosion scores for incisal/occlusal surfaces of upper teeth. $c$, Percentage or erosion scores for palatal surfaces of upper teeth. Green, scores 0-I; red, score 2; purple, score 3-4; yellow, score 9 excluded.

and extrinsic aetiological factors that may cause erosion for some time. Secondly, many studies including the UK Child Dental Health Survey of 1993, ${ }^{12}$ have only examined anterior teeth and have used diverse measurement criteria. The current investigation and those on other 14-year-olds reported by Milosevic et al. ${ }^{13}$ and Bartlett et al. ${ }^{14}$ have all used the Tooth Wear Index of Smith and Knight. ${ }^{22}$

They have all paid considerable attention to the problems inherent in measuring tooth wear consistently and have therefore undertaken reproducibility studies. Establishing reliable prevalence data for tooth wear, particularly that mainly of an erosive nature has proved difficult. The data from the two previously published studies ${ }^{13,14}$ can be directly compared with the current results. Although the data from Liverpool ${ }^{13}$ were from a random sample, those from London were from a cluster sample. Milosevic et al. ${ }^{13}$ reported that $30 \%$ of their total sample of 1035 children had at least one tooth with dentine exposed but this was largely on occlusal and incisal surfaces. If the incisal and occlusal surfaces are excluded as being most likely to be affected by attrition then $8 \%$ of the total sample

Table 5 Prevalence and severity of erosion in 4 I 8, I4-year-olds Birmingham U.K. school children by ACORN classification. ${ }^{24}$

\begin{tabular}{lcccc}
$\begin{array}{l}\text { ACORN } \\
\text { Categories }\end{array}$ & $\begin{array}{l}\text { Number of } \\
\text { children }\end{array}$ & Low erosion & Moderate erosion & Severe erosion \\
\hline A Thriving & 30 & $69 \%$ & $31 \%$ & 0 \\
B Expanding & 13 & $53 \%$ & $42 \%$ & 0 \\
C Rising & 25 & $52 \%$ & $48 \%$ & 0 \\
D Settling & 89 & $54 \%$ & $46 \%$ & 0 \\
E Aspiring & 72 & $53 \%$ & $43 \%$ & $4 \%$ \\
F Striving & 189 & $39 \%$ & $60 \%$ & $1 \%$ \\
\hline
\end{tabular}




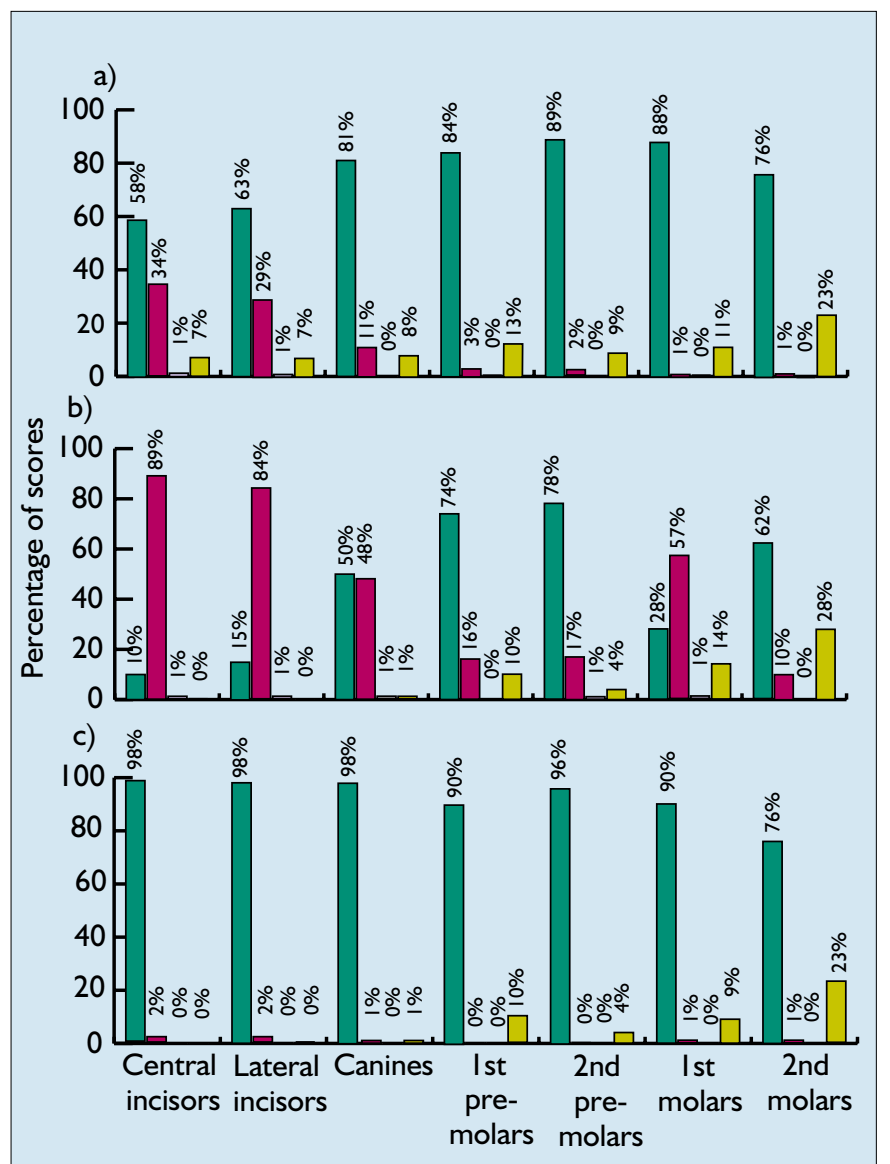

Fig. 3 Erosion in 4 18, 14-year-old Birmingham school children.

a, Percentage of erosion scores for buccal/labial surfaces of lower teeth. $b$, Persentage of erosion scores for incisal/occlusal surfaces of lower teeth. c, Percentage or erosion scores for palatal surfaces of lower teeth. Green, scores 0-I; red, score 2; purple, score 3-4; yellow, score 9 excluded.

had exposed dentine on other surfaces. This compares with $9.7 \%$ in the present study. The investigation of 210 London 11 to 14 year old school children from a small number of schools published by Bartlett et al. ${ }^{14}$ showed that although erosion of enamel on incisor teeth was common, with $57 \%$ of those children having erosion on more than ten teeth, erosion into dentine was relatively uncommon. The tooth wear recorded was less than in the Liverpool and Birmingham studies, but the median age was lower at 12 years. Teenage years may be a time at which wear progresses rapidly.

Although no differences were observed between males and females in the London ${ }^{14}$ study, there was significantly more tooth wear in boys than in girls in Liverpool ${ }^{13}$ with $35 \%$ boys having exposed dentine compared with $24 \%$ of girls. The present study has also shown statistically significant differences between the genders with $56 \%$ of boys showing moderate to severe tooth wear compared with $49 \%$ of girls. These findings support those shown in adults by Hugoson et al. ${ }^{25}$ and Smith and Robb ${ }^{26}$ but the tooth wear in adults is more likely to be attributed to a combination of attrition, abrasion and erosion rather than a main aetiological factor of erosion in the younger age-group.

There was a total of 1,988 14 year-old children on the nominal roll of all the 35 secondary schools in Birmingham. The cluster random sample involved children from a relatively large number of these schools with a multi-ethnic population from a variety of socio-economic backgrounds. The 12 schools selected were considered to be representative of the total number and ranged from single sex grant maintained and grammar schools to inner city comprehensives. The Ethics Committee from whom approval for this study was obtained refused to allow inclusion of ethnic background in the investigation. However, the 1991 Census for Birmingham 8-yearold children (who would have been 15 years old when the present study was undertaken) showed that $65 \%$ were Caucasian, $25 \%$ Asian and $8 \%$ Afro-Caribbean. ${ }^{27}$ The ethnic distribution was expected to be similar to this in the cluster random sample involved.

There is no information from any published studies concerning the relationship between ethnic background and erosion. There has only been limited information on the relationship of socio-economic grouping and erosion. Milosevic et al. ${ }^{13}$ classified 14 year-old Liverpool children from 10 schools involved according to the socioeconomic status of the electoral ward in which the schools were located.

In the current study the post-code for each child was obtained and they were then individually placed into an ACORN category. ${ }^{24}$ This is a more discriminatory process and should enable more accurate data to be collected. The ACORN classification has been used in several medical and dental investigations. ${ }^{24,28-33}$ It has been stated that the ACORN groups were as good as, or better than social class groupings such as the Registrar General's Classification of Social Class. They also get over the problems of unemployment and single parent families. Evidence suggests that measures of the socio-economic characteristics of neighbourhoods are better predictors of the health status of population sub-groups than measures of the socio-economic characteristics of individuals or households. ${ }^{34}$ Milosevic et al. ${ }^{13}$ used electoral ward classification and found that overall there was a slight positive association between the prevalence of tooth wear and the Jarman score, hence children in the schools in the deprived areas showed a higher prevalence of tooth wear.

The differences in socio-economic grouping were evident in the Birmingham children; $61 \%$ of those who were in the lowest socioeconomic category of F (Striving) had moderate to severe erosion compared with only $31 \%$ of those in the highest group A (Thriving). These data for the permanent dentition are completely at variance with the only study that has reported information on primary teeth. ${ }^{19}$ Young children from low socio-economic groups had significantly less erosion than those from the higher socio-economic groups. These apparently contradictory findings are probably related to the differing aetiological and environmental factors that are in operation at different ages. Teenagers may experience different life-style influence and do not have the same dependency on their parents for their dietary and soft drink intake, as do young children. They also do not have the same parental supervision (or lack of it) for their oral hygiene practices. Additionally, there may be considerable differences in gastro-oesophageal reflux and vomiting between these age groups. All of these factors may be of direct aetiological relevance to erosion.

Thus, this study has shown that approximately half of 14 -yearolds have appreciable tooth wear and significant erosion, and this is more prevalent in lower socio-economic groups. It is therefore important to identify those at risk of developing clinical problems so that preventive advice can be targeted. Further investigation is required to identify and quantify risk factors.

The authors would like to thank all the children and schools for their co-operation in this study and particular thanks to Drs. Martin Boote and Julie Waplington for their help during the clinical examinations at the schools. Also to Dr Debbie White for assistance and advice with the 'Survey-Plus' package analysis.

1 Kelleher M, Bishop K. Tooth surface loss: an overview. Br Dent J 1999; 186 61-66.

2 Milosevic A. Eating disorders and dentist. Br Dent J 1999; 186: 109-113.

3 Shaw L, Smith, A J. Dental erosion - the problem and some practical solutions. Br Dent J. 1999; 186: 115-118.

4 Capp N J. Occlusion and splint therapy. Br Dent J 1999; 186: 217-222.

5 Faigenblum, M. Removable prostheses. Br Dent J 1999; 186: 273-276.

6 King P A. Adhesive techniques. Br Dent J 1999; 186: 321-326.

7 Wickens J L. Prevention and maintenance. Br Dent J 1999; 186: 371-376.

8 Wickens J L. Dealing with failures. Br Dent J 1999; 186: 443-446.

9 Harley K. Tooth wear in the child and the youth. Br Dent J 1999; 186: 492-496. 
10 Ibbetson R. Treatment planning. Br Dent J 1999; 186: 552-558.

11 Ward V J. Surgical crown lengthening. Br Dent J 1999; 186: 21-24.

12 O'Brien M. Children Dental Health in the United Kingdom 1993. Office of Population Censuses and Surveys. 1994. HMSO. London 1994.

13 Milosevic A, Young P J, Lennon M A. The prevalence of tooth wear in 14year-old school children in Liverpool. Community Dent Health 1994; 11: 83-86.

14 Bartlett D W, Coward P Y, Nikkah C, Wilson R F. The prevalence of tooth wear in a cluster sample of adolescent schoolchildren and its relationship with potential explanatory factors. Br Dent J 1998; 184: 125-129.

15 O'Sullivan E A, Curzon M E J, Roberts G J, Milla P J, Stringer M D. Gastroesophageal reflux in children and its relationship to erosion of primary and permanent teeth. Eur J Oral Sci 1998; 106: 765-769.

16 Bartlett D W, Evans D F, Anggiansah A, Smith B G N. A study of the association between gastro-oesophageal reflux in children and palatal erosion. Br Dent J 1996; 181: 125-132.

17 Shaw L, Smith A J. Erosion in children. An increasing clinical problem? Dental Update 1994; 21:103-106.

18 Millward A, Shaw L, Smith A J, Rippin J W, Harrington E. The distribution and severity of tooth wear and relationship between erosion and dietary constituents in a group of children. Int J Paed Dent 1994; 4: 151157.

19 Millward A, Shaw L, Smith A J. Dental erosion in four-year-old children from differing socioeconomic backgrounds. J Dent Child 1994; 61; 263266.

20 Davis W B, Winter P J. Dietary erosion of adult dentine and enamel. $\mathrm{Br}$ Dent J 1977; 143: 116-119.

21 Jaeggi T, Lussi A. Toothbrush abrasion of erosively altered enamel after intraoral exposure to saliva: An in situ study. Caries Res. 1999; 33: 455-461.

22 Smith B G N, Knight J K. An index for measuring the wear of teeth. Br Dent J 1984; 156: 435-438.

23 CACI Information Services (1993): ACORN Analysis-Targeting for the 90's.
London: CACI Ltd.

24 White D, Anderson R J. Children's dental health under the capitation scheme. Comm Dent Health 1996; 13: 22-46.

25 Hugoson A, Bergendal T, Ekfeldt A, Helkimo M. Prevalence and severity of incisal and occlusal tooth wear in an adult Swedish population. Acta Odontal Scand 1988; 46: 255-265.

26 Smith B G N, Robb N D. The prevalence of toothwear in 1007 dental patients. J Oral Rehabil 1996; 23: 232-239.

27 Health Birmingham 2000 Information Group (1993). The 1991 Census and Health of Birmingham. Birmingham: Health Birmingham 2000 Information Group.

28 Morgan M, Chinn S. ACORN group, social class and child health. Epidem. and Commun Health 1983; 37: 196-203.

29 Sarll D, Whittle J, Mackie I. The use of a classification of residential neighbourhood as a health-related variable in service planning for dentistry. Comm Dent Health 1984; 1: 115-123.

30 Morgan M, Reynolds A, Morris R, Allsop M, Rona R. Who uses child health clinics and why: a study of a deprived inner city district. Health Visitor 1989; 62: 244-247.

31 Booth V, Ashley F. The oral health of a group of 15-17 year old British schoolchildren of different ethnic origin. Comm Dent Health 1989; 6: 195205.

32 Elley K M, Charlton J. Prevalence of dental enamel defects in 6, 7 and 8year-old children resident in West Bromwich, Sandwell, UK. Comm Dent Health 1993; 10: 11-21.

33 Elley K M, Langford J W. The use of a classification of residential neighbourhood (ACORN) to demonstrate differences in dental health of children resident within the South Birmingham health district and of different socio-economic backgrounds. Comm Dent Health 1993; 10: 131-138.

34 Locker D. Measuring social inequality in dental health services research: individual, household and area-based measures. Comm Dent Health 1993; 10: $139-150$. 